\title{
ON THE SECOND SPECTRUM OF LATTICE MODULES
}

\author{
Narayan Phadatare, Sachin Ballal \\ AND \\ VILAS KHARAT \\ Department of Mathematics \\ Savitribai Phule Pune University \\ Pune-411 007, India \\ e-mail: a9999phadatare@gmail.com \\ ballalshyam@gmail.com \\ laddoo1@yahoo.com
}

\begin{abstract}
The second spectrum $\operatorname{Spec}^{s}(M)$ is the collection of all second elements of $M$. In this paper, we study the topology on $\operatorname{Spec}^{s}(M)$, which is a generalization of the Zariski topology on the prime spectrum of lattice modules. Besides some properties, $\operatorname{Spec}^{s}(M)$ is characterized and the interrelations between the topological properties of $\operatorname{Spec}^{s}(M)$ and the algebraic properties of $M$, are studied.
\end{abstract}

Keywords: second element, prime element, maximal element, minimal element, spectral space.

2010 Mathematics Subject Classification: 06D10, 06E10, 06F10.

\section{REFERENCES}

[1] H. Ansari-Toroghy and F. Farshadifar, The Zariski topology on the second spectrum of a module, Algebr. Colloq. 21 (2014) 671-688. doi:10.1142/S1005386714000625

[2] M.F. Atiyah and I.G. Macdonald, Introduction to Commutative Algebra (AddisonWesley, 1969).

[3] E.A. AL-Khouja, Maximal elements and prime elements in lattice modules, Damascus Univ. Basic Sci. 19 (2003) 9-20.

[4] S. Ballal and V. Kharat, On generalization of prime, weakly prime and almost prime elements in multiplicative lattices, Int. J. Algebra 8 (2014) 439-449. doi:10.12988/ija.2014.4434 
[5] S. Ballal and V. Kharat, Zariski topology on lattice modules, Asian Eur. J. Math. 8 1550066 (2015) (10 pages). doi:10.1142/S1793557115500667.

[6] S. Ballal and V. Kharat, On $\phi$-absorbing primary elements in lattice modules, Algebra (2015) 183930 ( 6 pages). doi:10.1155/2015/183930

[7] S. Ballal, M. Gophane and V. Kharat, On weakly primary elements in multiplicative lattices, Southeast Asian Bull. Math. 40 (2016) 49-57.

[8] M. Behboodi and M.R. Haddadi, Classical Zariski topology of modules and spectral spaces I, Int. Electron. J. Algebra 4 (2008) 104-130.

[9] M. Behboodi and M.R. Haddadi, Classical Zariski topology of modules and spectral spaces II, Int. Electron. J. Algebra 4 (2008) 131-148.

[10] F. Callialp, U. Tekir and G. Ulucak, Comultiplication lattice modules, Iranian Journal of Science and Technology, A2 39 (2015) 213-220.

[11] F. Çallialp, G. Ulucak and U. Tekir, On the Zariski topology over an L-module M, Turk. J. Math. doi:10.3906/mat-1502-31

[12] M. Hochster, Prime ideal structure in commutative rings, Trans. Amer. Math. Soc. 142 (1969) 43-60. doi:10.1090/S0002-9947-1969-0251026-X

[13] V. Joshi and S. Ballal, A note on n-Baer multiplicative lattices, Southeast Asian Bull. Math. 39 (2015) 67-76.

[14] J.A. Johnson, a-adic completions of Noetherian lattice modules, Fund. Math. 66 (1970) 341-371.

[15] C.P. Lu, The Zariski topology on the prime spectrum of a module, Houston J. Math. 25 (1999) 417-425.

[16] J.R. Munkres, Topology, Second Ed. (Prentice Hall, New Jersey, 1999).

[17] R.L. McCasland, M.E. Moore and P.F. Smith, On the spectrum of a module over a commutative ring, Comm. Algebra 25 (1997) 79-103. doi:10.1080/00927879708825840

[18] N.K. Thakare, C.S. Manjarekar and S. Maeda, Abstract spectral theory II: minimal characters and minimal spectrums of multiplicative lattices, Acta Sci. Math. 52 (1988) 53-67.

[19] N.K. Thakare and C.S. Manjarekar, Abstract spectral theory: Multiplicative lattices in which every character is contained in a unique maximal character, in: Algebra and Its Applications (Marcel Dekker, New York, 1984), pp. 265-276.

[20] N. Phadatare, S. Ballal and V. Kharat, On the quasi-prime spectrum of lattice modules, (Communicated). 